\title{
SÍNDROME DE MUNCHAUSEN POR PROCURAÇÃO: ESTUDO INTRODUTÓRIO NA PERCEPÇÃO JURÍDICA
}

\author{
Altamy Lopes da Silva ${ }^{1}$ \\ Luciana Neves ${ }^{2}$
}

\begin{abstract}
RESUMO
O presente artigo tem como viés principal mostrar a Síndrome de Munchausen por Procuração. Distúrbio fictício em que os indivíduos, na maioria das vezes cuidadores ou genitores, provocam ou agravam doenças físicas ou psicológicas em outros, submetendo-os a tratamentos desagradáveis e desnecessários, causando-lhes lesões permanentes e muitas vezes até levando-os a óbito. Tal síndrome pode ter influência de fatores externos que fazem com que os portadores visem possibilidades de serem reconhecidos e de ganhar atenção. Neste artigo abordaremos os conceitos, histórias e casos envolvendo a Síndrome de Munchausen por Procuração, bem como suas consequências e os resultados que trazem para o ordenamento jurídico.
\end{abstract}

Palavras-chave: Síndrome de Munchausen. Distúrbio fictício. Ordenamento Jurídico.

Data de submissão: $23 / 03 / 2020$

Data de aprovação: 04/05/2020

\begin{abstract}
This article has the main purpose of showing the Munchausen Syndrome by Proxy. Fictitious disorder in which individuals, most often caregivers or parents, cause or aggravate physical or psychological illnesses in others, subjecting them to unpleasant and unnecessary treatments, causing permanent injuries and often even leading them to death. This syndrome may be influenced by external factors that make patients aim at possibilities of being recognized and gaining attention. In this article we will cover the concepts, stories and cases involving the Munchausen Syndrome, as well as its consequences and the results they bring to the legal system.
\end{abstract}

Key words: Munchausen Syndrome. Fictitious Disorder. Legal System.

1 Graduando do Curso de Direito da Faculdade Metropolitana da Grande Recife. E-mail: altamyster@gmail.com

2 Orientadora/Professora da Faculdade Metropolitana da Grande Recife. E-mail: luciananv2003@yahoo.com.br 


\section{INTRODUÇÃO}

No ano de 1951 um médico inglês chamado Richard Asher descreveu pela primeira vez uma síndrome em um paciente que, de forma aguda e dramática, se mostrava aparentemente doente, reproduzindo de forma convincente e recorrente todos os sintomas. Como consequência, era submetido à investigação diagnóstica e tratamentos desnecessários.

A Síndrome de Munchausen por Procuração é uma variante da Síndrome de Munchausen. Nela, o indivíduo adoece a outrem, com a finalidade de obter atenção sobre si. Tal síndrome é também usada como forma de alienação parental e ocorre quando os pais adoecem os filhos por inúmeras vezes, submetendo-os a tratamentos desnecessários, correndo o risco até de matá-los, sob o pretexto de deixá-los mais próximos. Há manipulação de forma sucinta para que no momento da separação a criança escolha um dos pais. O Código Penal prevê em seu artigo 132 (expor a vida ou a saúde de outrem a perigo direto e iminente) pena de detenção de três meses a um ano, se o fato não constitui crime mais grave. (JESUS, 2010).

Neste trabalho abordaremos a SMP usada como alienação parental, bem como suas consequências na esfera penal. Foi feito um estudo descritivo com a observância de casos aplicados à Síndrome de Munchausen por Procuração, através de dados coletados da mídia, com o fulcro de esclarecer de forma ampla o que é a síndrome e suas consequências na esfera jurídica.

\section{TRANSTORNO FICTÍCIO: O PACIENTE IMAGINÁRIO}

Os termos transtorno, distúrbio e doença conciliam-se aos termos mental, psíquico e psiquiátrico para apresentar ou descrever qualquer anormalidade, sofrimento ou comprometimento de ordem psicológica e/ou mental. Síndrome (do grego "syndromé", cujo significado é "reunião") é um termo bastante utilizado em Medicina e Psicologia para caracterizar um conjunto de sinais e sintomas que definem uma determinada patologia ou condição. O adjetivo fictício significa artificial, convencional, aquilo que não é racion al. (HOUAISS, 2009). 
Os transtornos fictícios, por ser uma doença pouco diagnosticada, têm como característica principal os sintomas físicos ou psicológicos, uma vez que o paciente tem os sintomas da doença por ele criada, tendo assim suas peculiaridades. Seu diagnóstico pode ser alcançado por observação simples ou por meio de exclusão de outros sintomas, embora não o exclua totalmente, uma vez que o paciente tem as fortes características da doença por ele descrita. Os resignados costumam vaguear por vários médicos e hospitais diferentes com o intuito de obter novo tratamento. As causas ainda são desconhecidas, muito embora seja um distúrbio psicológico considerado grave.

Nele, a pessoa simula a doença ou agrava algo preexistente como simular delírios quando há históricos de distúrbios psicológicos. Pessoas com esse tipo de transtorno costumam exagerar ao falar da sua doença, mas quando solicitados a dar mais detalhes explicam de forma vaga. Suas queixas são geralmente de dores e há exigência de analgésicos. Quando explorado o seu desconforto físico pelo médico o resultado é negativo. Então são submetidas a vários exames e intervenções cirúrgicas e quando percebem que são pegos mentindo elas negam ou saem do hospital rapidamente.

Os distúrbios têm predominância de sintomas psicológicos. Neles estão contidos a produção intencional ou fingimento de comportamentos iguais ao de doença mental, em que o indivíduo tem o objetivo de estar no lugar do paciente. Não é de fácil diagnóstico, pois quando sentem que estão sendo observados pioram os sintomas. Na maioria das vezes eles se queixam de depressão, perda de memória, alucinações e sintomas de estresse póstraumático (embora na maioria dos casos sem trauma algum), mostrando que tem algum transtorno mental. Para Feldman \& Brown (apud CASCAIS, 2012), os pacientes podem fingir sinais (convulsões e desmaios), exagerar e dramatizar seus relatos ou induzir doenças como a manipulação excessiva de uma ferida.

Existe outra modalidade de transtorno fictício, antes chamado de distúrbio fictício por procuração. Geralmente essa modalidade é observada nos casos em que o distúrbio fictício pode ser imposto a outra pessoa, na modalidade física ou psicológica. Em sua maioria por cuidadores ou seus genitores que produzem ou falsificam intencionalmente sintomas ou sinais físicos/psicológicos, adoecendo uma pessoa que está sobre seus cuidados e muitas vezes dificultando o diagnóstico médico, causando lesões graves permanentes, chegando até a levar o indivíduo a óbito. A forma mais grave foi chamada de Síndrome de Munchausen e sua variante, a Síndrome de Munchausen por Procuração, tem como foco principal o distúrbio fictício imposto ao outro. 


\section{SÍNDROME DE MUNCHAUSEN (SM): CONCEITO E ORIGEM}

No ano de 1951 o psiquiatra Inglês Richard Asher descobriu uma forma particular de transtorno caracterizado pela tendência patológica de mentir (também chamada pneumologia fantástica). O nome é uma referência a um alemão que ficou conhecido na época como o homem mais mentiroso do mundo. Karl Frederich Hieronymus, o Barão de Munchausen, viveu no século XVIII entre os anos de 1720 a 1797 e contava histórias fantásticas sobre os anos em que foi militar do exército russo. A sua imaginação não tinha limites e suas histórias depois se transformaram em livros e filmes. Penna (apud BRAGA, 2007) fala sobre o nome ser atribuído ao Barão e ressalta:

\footnotetext{
A doença recebeu o nome de Síndrome de Munchausen, pois assim como o Barão, os pacientes também são peregrinos viajando de hospitais em hospitais, contando histórias fantásticas sobre doenças, e inventando sintomas com que captam a atenção dos médicos, exibindo a arte de verdadeiros mágicos ilusionistas. (BRAGA, 2007, p. 4).
}

Os pacientes acompanhados por Asher tinham em comum a peregrinação de um hospital a outro e a recorrente simulação, mais ou menos consciente, de doenças físicas. A Síndrome de Munchausen é um transtorno fictício de difícil diagnóstico, em que o indivíduo provoca de forma compulsiva, deliberada e recorrente em si ou finge ter doenças com a principal finalidade de conquistar atenção e simpatia de quem o cerca. Segundo Kaplan e Sadock (1999), são ainda atribuídos outros nomes como síndrome de paciente profissional e síndrome de dependência hospitalar.

A síndrome em questão não é igual à hipocondria, na qual a pessoa acredita realmente estar doente. $\mathrm{Na} \mathrm{SM}$ o indivíduo sabe que não sofre com doença alguma, mas quer estar doente. Ele promove em si sintomas da doença e procura tratamentos sem o interesse de ganhos secundários, passando por vários hospitais e sendo submetido a várias intervenções médicas. O indivíduo, organicamente, não é portador de nenhuma doença, mas visa ocupar o lugar de paciente a fim de ganhar atenção e cuidados médicos com essa posição, podendo comportar-se "falsamente" frente à equipe hospitalar.

Ela é considerada pelos pesquisadores como um distúrbio fictício, pois existe a necessidade de simulação da doença, sendo incluída na décima edição da Classificação Internacional de Doenças (CID-10) na categoria de produção intencional ou imitação de sintomas ou disfunções, tanto físicas quanto psicológicas (transtorno factício). Seu diagnóstico é obtido de forma ainda muito precária, sendo feito principalmente por meio de observação, o que não torna o método muito preciso. Poucos são os artigos escritos sobre a síndrome, mostrando assim a necessidade de um aprofundamento no que tange ao seu 
estudo.

Segundo Andrade \& Pereira-Silva (2005), em seu artigo científico publicado no Jornal Brasileiro de Pneumologia, a Síndrome de Munchausen é um distúrbio psiquiátrico cujo diagnóstico exige alto índice de suspeição. A hemoptise fictícia resulta de trauma auto infligido na faringe ou de mordedura intencional da própria língua. Os autores alertam a classe médica quanto à possibilidade de que o material eliminado pela cavidade oral resulte da injeção e armazenamento temporário de sangue autólogo, colhido de uma veia, pelo próprio paciente.

\section{SÍNDROME DE MUNCHAUSEN POR PROCURAÇÃO (SMP)}

Ingleses e americanos deram início aos estudos de casos na década de 70 e artigos de revisão de literatura só apareceram na década de 80, ou seja, após 10 anos dos primeiros registros. Israel foi o primeiro país de língua não inglesa a ter uma publicação sobre o assunto. Somente na metade dos anos 80 foram encontrados registros de casos na França, Itália, Espanha e Alemanha.

Jayme Murahovschi foi um dos primeiros médicos brasileiros a descrever um caso de SMP no Brasil, no Jornal de Pediatria. Ele observou, após um atendimento de rotina, uma menina de três anos, de nome Polyana, que foi levada ao hospital pela sua mãe após uma queda. Essa criança melhorou, mas constantemente o ouvido direito continuava sangrando. Na época, em 1996, foram feitos todos os exames possíveis para encontrar a causa do sangramento. No entanto todos os exames davam normais. Até que os médicos começaram a desconfiar da própria mãe e descobriram que o sangue encontrado no ouvido da criança não era o dela. Posteriormente notaram que já não era mais sangue e sim mercúrio-cromo. (MURAHOVSCHI at al, 1996).

A SMP é uma vertente da Síndrome de Munchausen que tem como foco principal o adoecimento do outro e não de si mesmo. Geralmente ocorre com frequência contra crianças, pois a mãe cria os sintomas da doença no filho, levando-o de forma reiterada e recorrente aos hospitais.

Na maioria das vezes a mãe se mostra muito atenciosa com o filho a quem ela adoeceu, sendo quase impossível a desconfiança de que é ela quem provoca os sintomas. Jayme Murahovschi diz que a mãe é afetuosa e cuidadosa e permanece quase o tempo todo com a criança hospitalizada. Sua aparente devoção sensibiliza e engana a equipe médica com a qual se estabelece uma relação calorosa. (MURAHOVSCHI at al, 1996). 
No Manual Diagnóstico e Estatístico de Transtornos Mentais (DSM-IV, 1995, p. 685) a Síndrome de Munchausen por Procuração é descrita sob o título de Transtorno Fictício por Procuração, sendo caracterizada pela produção intencional ou simulação de sintomas físicos ou psicológicos em outra pessoa que está sobre seus cuidados. A motivação para o comportamento é assumir o papel de doente através da outra pessoa.

\section{CASOS SOBRE A SÍNDROME DE MUNCHAUSEN POR PROCURAÇÃO}

\section{Dee Dee e Gypsy}

Dee Dee e Gypsy moravam em um pequeno bangalô em Springfield e eram queridas pelos vizinhos. Dee Dee tinha 48 anos e fazia amigos com facilidade. Ela não trabalhava e cuidava da filha adolescente em tempo integral. Gypsy tinha aproximadamente 1,5m de altura, usava óculos, cadeira de rodas e se alimentava por um tubo. Às vezes, para sair de casa, era necessário um tubo de oxigênio que sua mãe carregava. Quem perguntava sobre o diagnóstico de sua filha ouvia como resposta uma longa lista de problemas de saúde: anomalias cromossômicas, distrofia muscular, epilepsia, asma severa, apneia do sono e problemas na vista. Dizia que sua filha sempre foi assim desde bebê. Gypsy passou um tempo na UTI neonatal porque teve leucemia quando era pequena. Sua mãe dizia que ela tinha tido problemas cerebrais e estudava em casa porque jamais conseguiria acompanhar seus colegas de escola.

Segundo ela, Gypsy tinha a idade cerebral de uma criança de sete anos e era importante lembrar-se disso. Por muitos anos Dee Dee contava a história de que fugiu com sua filha porque era vítima de abusos e que o avô paterno de sua filha a queimava com ponta de cigarro. Dizia também que seu ex-marido era caloteiro, alcoólatra e viciado em drogas. Fazia ainda piadas com os problemas da própria filha. Elas, de fato, pareciam muito felizes e recebiam doações da Fundação Michael Riche.

No dia 14 de junho de 2015 essa história tomou um rumo bem diferente quando uma mensagem foi postada no Facebook de Dee Dee. Amigos chocados acharam que sua conta havia sido raqueada. Ligavam, mas ninguém atendia ao telefone. Quando a polícia entrou encontrou o corpo de Dee Dee na cama. Aparentemente estava morta há vários dias, esfaqueada, e não havia nenhum sinal da menina. Uma vizinha relatou que Gypsy tinha um suposto namorado. A polícia a encontrou na casa dele. O xerife descobriu uma história inacreditável. A garota não usava mais a cadeira de rodas e andava normalmente. Não usava o tanque de oxigênio, a musculatura parecia normal, não tomava mais remédios, não 
tinha mais a cabeça raspada e não parecia doente. A menina frágil que todos conheciam era uma farsa, criada pela própria mãe. A menina nasceu saudável, mas, por ter apneia do sono, sua mãe a levava a inúmeros hospitais, relatando inúmeros problemas de saúde. Gypsy e Nicolas foram indiciados e presos por terem planejado o assassinato de Dee Dee. (PUTINI, 2019).

\section{Caso Kelly Renee}

Kelly Renee Turner foi indiciada pela Justiça por 13 crimes, incluindo abuso infantil, roubo e fraude de doações no caso da morte da filha, Olivia Grant, em 2017. Turner também é acusada de ter conseguido 539 mil dólares, de modo fraudulento, do Medicaid, serviço de saúde do governo americano.

O caso resultou na prisão da mãe assassina. Antes da morte da filha ela ainda levantou doações e fez campanha para custas hospitalares e para que a filha realizasse alguns desejos antes de morrer. Esse é mais um caso de Síndrome de Munchausen por Procuração que teve um final horrível para a vítima. Laudos médicos descobriram que a menina não tinha nenhuma doença terminal. A mãe alimentava a filha por um tubo e, mesmo sabendo da possibilidade da filha vir a óbito, não hesitou em continuar com os maus tratos. (ORLANDO, 2019).

Nos casos relatados é notório a SMP e há a percepção de que existe uma violação dos direitos, pois tais prejuízos causados são irreparáveis. $O$ papel da mãe foi imprescindível para o acometimento das doenças apresentadas pelos seus filhos em ambos os casos. No Brasil, o direito à vida é fundamental, individual e inviolável, garantido na Constituição Federal no caput do $5^{\circ}$ artigo. É também direito resguardado em cláusula pétrea no art. $60,4^{\circ}$ parágrafo. (BRASIL, 1988).

\section{A SÍNDROME DE MUNCHAUSEN E O DIREITO}

A Síndrome de Munchausen por Procuração ainda é pouco tratada no Direito brasileiro, tendo em vista o número de casos ainda não tipificados, pelos poucos artigos e obras escritas sobre o assunto e pelo difícil diagnóstico e laudos médicos ainda muito precários em sua forma de detecção. Por ser uma síndrome pouco observada, passam despercebidos os inúmeros casos existentes, mas já é possível ver uma pequena evolução na observação de alguns casos de alienação parental envolvendo a SMP. 
Em outros países como os Estados Unidos, torna-se mais corriqueiro a aplicação e observância nos casos de alienação parental onde há a tutela do Direito Civil, bem como suas consequências no Direito Penal, uma vez que em algumas ocasiões o indivíduo tem como viés a obtenção de lucros. Muitas vezes há lesão corporal da criança que está sob a guarda do portador da SMP e, em casos mais graves, óbitos por ingestão de medicamentos ou submissão a tratamentos desnecessários.

\section{Síndrome de Munchausen por Procuração e a Alienação Parental}

A alienação parental é uma tentativa de desqualificação do parceiro, adotada por um dos cônjuges, quando há a separação do casal, impedindo que a criança mantenha o vínculo afetivo com aquele que não ficou com a guarda. Nessa disputa de poder a criança é quem sofre, estando ali como um cabo de guerra em que ela é a parte mais frágil e o centro principal da disputa judicial. É importante ressaltar que, apesar de ser um fenômeno visível recente, essa conduta já ocorre há muito tempo com maior ou menor intensidade. Com o Código Civil de 2002, o legislador, nos artigos 1583 e 1584, reafirmou a guarda compartilhada e o compartilhamento das responsabilidades dos pais para como os filhos, seguido pelo advento da lei 4.053/08.

Há condutas que são consideradas como alienação parental descritas na lei, mas como o direito de família é muito dinâmico, também é possível que existam outras formas não prescritas em lei.

Em 1985 o psiquiatra infantil Richard Gardner deu conceito e nome à Síndrome da Alienação Parental (SPA), na qual a criança ou adolescente sente abominação, desprezo ou rejeição em relação a um de seus genitores. A Síndrome da Alienação Parental (SAP) é um distúrbio que surge inicialmente no contexto das disputas em torno da custódia infantil. Sua primeira manifestação verifica-se numa campanha que não tem justificação. Esta síndrome resulta da combinação de um programa de doutrinação dos pais (lavagem cerebral) juntamente com a figura parental que está na mira desse processo. (ANGELIS NETO, 2019).

No século XVIII a filosofia descrevia sobre alienação como a abdicação de liberdades individuais e inerentes ao Estado, ou seja, quando se abria mão de direitos em benefício estatal. No sentido filosófico, entende-se por alienação o processo ou estado em que algo ou alguém é ou se converte em um indivíduo estranho para si próprio (distante, desconhecido ou alheio, por exemplo) perdendo a noção de sua identidade e valor como 
indivíduo. Por essa razão, na filosofia, a alienação está relacionada com o conceito de "vazio existencial". A origem da SAP ocorre exatamente quando a mãe percebe o interesse do pai em preservar a convivência afetiva com a criança e a usa de forma vingativa perante ressentimentos advindos da época do relacionamento ou da separação, programando o filho para odiar e rejeitar o pai sem nenhuma justificativa plausível. Nesse sentido, discorre Maria Berenice Dias (2009):

\begin{abstract}
Muitas vezes a ruptura da vida conjugal gera na mãe sentimento de abandono, de rejeição, de traição, surgindo uma tendência vingativa muito grande. Quando não consegue elaborar adequadamente o luto da separação, desencadeia um processo de destruição, de desmoralização, de descrédito do ex-cônjuge. Ao ver o interesse do pai em preservar a convivência com o filho, quer vingar- se, afastando este do genitor. Para isso cria uma série de situações visando a dificultar ao máximo ou impedir a visitação. Leva o filho a rejeitar o pai, a odiá-lo. (DIAS, 2009).
\end{abstract}

A alienação parental é descrita no ordenamento jurídico no art. $2^{\circ}$ da lei $n^{\circ}$ 12.318/10 e definida assim:

Considera-se ato de alienação parental a interferência na formação psicológica da criança ou do adolescente promovida ou induzida por um dos genitores, pelos avós ou pelos que tenham a criança ou adolescente sob a sua autoridade, guarda ou vigilância para que repudie genitor ou que cause prejuízo ao estabelecimento ou à manutenção de vínculos com este. (BRASIL, 2010).

A SMP está presente nos casos de alienação parental, pois há alguns casos em que um dos genitores adoece o filho com a intenção de afastá-lo de forma temporária ou permanente. Acontece com frequência com os genitores que detêm a guarda, no intuito de que a criança se apegue por ser ela a cuidadora, e assim despreze o outro. Também pode existir a coação psicológica, em que um dos genitores provoca sintomas de doenças psíquicas (perturbação mental, convulsões, etc.), afastando o outro genitor, alegando que só ela tem a forma, o tempo e os cuidados necessários para o tratamento da criança.

\title{
A SÍNDROME DE MUNCHAUSEN POR PROCURAÇÃO CONSTITU I PRÁTICA DELITUOSA
}

Para a doutrina o conceito de crime se divide em tipos que é definido como formal, material, híbrido ou misto e analítico. A criminologia nos diz que crime é um fenômeno complexo e variável que independe da lei e passa por outros fatores. No sentido social existem dois aspectos que dividem alguns doutrinadores: o primeiro deles entende que o fato ocorre quando o indivíduo fere uma norma social jurídica ou quando a sociedade tacha o sujeito como criminoso. O direito penal estuda só o fenômeno jurídico enquanto a criminologia estuda o fenômeno social e individual. 
É bem verdade que a SMP traz consequências e sequelas profundas na vida de quem é submetido a tais práticas, uma vez que vários direitos inerentes a ela são auferidos. Dentre eles estão o direito à saúde descrito nos art. 196 a 200 da CF e o direito à vida descrito no art. $60 \S 4^{\circ}$ da Constituição Federal e que são considerados em nosso ordenamento jurídico como cláusula pétrea.

É importante ressaltar que tais pessoas possuem um grau de entendimento ou um consciente elevado demais para simplesmente serem tratados só como portadores de distúrbios fictícios. Elas não sentem remorsos e quando são indagadas por médicos ou outras pessoas tentam se evadir do local de forma abrupta ou trocam a criança de hospital para que não sejam detectados. Observa-se que por meio da SMP o indivíduo pode submeter o outro a uma condição degradante, medicamentos, tratamentos e cirurgias desnecessárias, o que caracteriza maus tratos. Às vezes são submetidos a lesões corporais graves. Nos casos apresentados as crianças não tiveram a oportunidade da primazia de seus direitos fundamentais, pois eram submetidas pelos adultos a um tratamento desnecessário e acabavam tendo sua saúde violada.

A regra constitucional determina que é dever da família, sociedade e do Estado garantir à criança e ao adolescente o direito à vida, à saúde, à alimentação, à educação, ao lazer, à convivência familiar e comunitária, entre outras, colocando-os a salvo de toda a forma de negligência, de violência e de crueldade. Paulo Gustavo Gonet Branco afirma que

Os direitos fundamentais participam da essência do Estado de Direito democrático, operando como limite ao poder e como diretriz para sua ação, ou seja, há uma garantia de direitos fundamentais inerente a todos onde as constituições democráticas têm um rol de valores que os direitos fundamentais revelam e positivam. Isso faz com que os direitos influam sobre todo o ordenamento jurídico, servindo de norte para a ação de todos os poderes constituinte. (BRANCO, 2013, p. 167).

É notório que o nosso ordenamento jurídico prevê o crime de maus tratos contra pessoas que detêm a guarda de outrem no artigo 136 do Código Penal, bem como suas penas previstas em seus parágrafos $1^{\circ}, 2^{\circ}$ e $3^{\circ}$ :

Expor a perigo a vida ou a saúde de pessoa sob sua autoridade, guarda ou vigilância, para fim de educação, ensino, tratamento ou custódia, quer privando-a de alimentação ou cuidados indispensáveis, quer sujeitando-a a trabalho excessivo ou inadequado, quer abusando de meios de correção ou disciplina: Pena detenção, de dois meses a um ano, ou multa. $\S 1^{\circ}$ - Se do fato resulta lesão corporal de natureza grave: Pena - reclusão, de um a quatro anos. $\S 2^{\circ}$ - Se resulta a morte: Pena - reclusão, de quatro a doze anos. $\S 3^{\circ}$ - Aumenta-se a pena de um terço, se o crime é praticado contra pessoa menor de 14 (catorze) anos.

É importante ressaltar que o art. $5^{\circ}$ do Estatuto da Criança e do Adolescente traz garantias que tutelam as formas de convívio e segurança entre os menores e seus genitores 
ou responsáveis. O ECA alega que nenhuma criança ou adolescente será objeto de qualquer forma de negligência, discriminação, exploração, violência, crueldade e opressão, punindo na forma da lei qualquer atentado, por ação ou omissão, aos seus direitos fundamentais. (BRASIL, 1990).

O Estatuto da Criança e do Adolescente também estabelece o sistema de garantia de direitos da criança e do adolescente vítima ou testemunha de violência. Descreve também a alienação parental como um ato de violência que traz para a criança uma interferência psicológica.

Fernado Capez, em sua obra "Curso de Direto Penal", diz que o direito possui a função de selecionar o comportamento humano mais gravoso e perigoso que pode colocar os valores fundamentais em risco para a sociedade, passando tais condutas a serem infrações penais, aplicando-lhe sanções penais. O juiz federal Alexandre de Moraes, em publicação na Revista Processo (Instituto Brasileiro de Direito Processual), n. 98, p. 84, diz que

A dignidade da pessoa humana: concede unidade aos direitos e garantias fundamentais, sendo inerente às personalidades humanas. Esse fundamento afasta a ideia de predomínio das concepções transpessoalistas de Estado e Nação, em detrimento da liberdade individual. A dignidade é um valor espiritual e moral inerente à pessoa, que se manifesta singularmente na autodeterminação consciente e responsável da própria vida e que traz consigo a pretensão ao respeito por parte das demais pessoas, constituindo-se um mínimo invulnerável que todo estatuto jurídico deve assegurar, de modo que, somente excepcionalmente, possam ser feitas limitações ao exercício dos direitos fundamentais, mas sempre sem menosprezar a necessária estima que merecem todas as pessoas enquanto seres humanos.

Os casos que envolvem a SMP podem desencadear alguns crimes, dentre eles podemos citar o que está previsto no artigo 132 do Código Penal: crime de exposição à saúde de outrem. Outro tipo de crime praticado pelos que se utilizam da SMP é o estelionato, pois o indivíduo cria situação para extorquir dinheiro, como disposto no caso Kelly Renee em que ela fazia campanhas para angariar fundos para a filha que estava em estado terminal, no falso intuito de proporcionar os últimos desejos de sua filha.

$\mathrm{O}$ caput do art. 171 do Código Penal abre um imenso leque para os vários modus operandi em que o indivíduo pode cometer a modalidade de estelionato. O crime é caracterizado quando alguém tenta “obter, para si ou para outrem, vantagem ilícita, em prejuízo alheio, induzindo ou mantendo alguém em erro, mediante artifício, ardil, ou 
qualquer outro meio fraudulento".

A lesão corporal descrita no art. 129 caput do Código Penal é mais um dos crimes praticados por portadores da SMP. Nesse mesmo entendimento descreve Cesar Roberto Bitencourt:

Lesão corporal consiste em todo e qualquer dano produzido por alguém, sem animus necandi, à integridade física ou à saúde de outrem. Ela abrange qualquer ofensa à normalidade funcional do organismo humano tanto do ponto de vista anatômico quanto do fisiológico ou psíquico. Na verdade é impossível uma perturbação mental sem um dano à saúde, ou um dano à saúde sem uma ofensa corpórea. O objeto da proteção legal é a integridade física e a saúde do ser humano. (BITENCOURT, 2018, p. 186).

Nessa modalidade de crime as mães provocam lesões no filho ou agravam lesões já existentes, bem como a manipulação de remédios desnecessários que na maioria das vezes deixam sequelas. É imprescindível ainda destacar o crime de homicídio, pois muitas vezes a criança submetida aos maus tratos vem a óbito. Neste mesmo sentido Nucci completa:

É a vontade do agente dirigida a um resultado determinado, porém vislumbrando a possibilidade de ocorrência de um segundo resultado, não desejado, mas admitido, unido ao primeiro. Por isso, a lei utiliza o termo "assumir o risco de produzi-lo". Nesse caso, de situação mais complexa, o agente não quer o segundo resultado diretamente, embora sinta que ele pode se materializar juntamente com aquilo que pretende o que lhe é indiferente. (NUCCI, 2012, p. 238).

No que tange aos acontecimentos de muitos casos a pessoa que envolve outro indivíduo com a Síndrome de Munchausen por Procuração tem ciência de que sua atitude prejudicará a outra, no entanto, suas ações culminam de forma direta em práticas consideradas pela doutrina e pela criminologia como delituosas. Muitas vezes ela pode ter um conhecimento prévio da existência da SMP e mesmo assim praticar atos que podem gerar sanções penais.

No Brasil temos penas aplicadas a outras formas de síndromes, como nos casos da síndrome de alienação parental. Quem tem problemas psicológicos está mais propenso ao cometimento de delito. Por mais que a conduta não esteja tipificada no rol de síndromes que desencadeiam em condutas delitivas, é notória a existência de crimes contra a vida e a saúde. 


\section{CONSIDERAÇÕES FINAIS}

Este trabalho viabilizou testificar que o transtorno fictício é um problema psicológico em que o individuo cria doença psicológica ou física com o intuito de receber atenção. A Síndrome de Munchausen é uma variante do transtorno fictício. A mesma não se confunde com hipocondria, pois enquanto nesta a pessoa realmente acredita ter a doença, o indivíduo com SM sabe que não tem doença alguma, no entanto deseja estar na condição de paciente. Quando interrogado sobre a sua "doença" ele foge de forma abrupta, procurando outro hospital para atendê-lo. A Síndrome de Munchausen por Procuração é outra variante do distúrbio fictício, pois o indivíduo, na maioria das vezes genitor ou cuidador, cria no outro doenças físicas ou psicológicas, levando-o de forma reiterada ao médico, submetendo-o de forma desnecessária a tratamentos que podem fazer mal a saúde e levar a óbito.

No Brasil a SMP é mais observada em casos envolvendo alienação parental, em que genitores se valem de tais prerrogativas para desqualificação do parceiro, impedindo que a criança mantenha um vínculo afetivo, promovendo o distanciamento daquele que ficou com a guarda. Para o nosso ordenamento jurídico a síndrome da alienação parental é apontada como uma forma de violência praticada contra a criança, o que constitui abuso infantil, pois prejudica de forma emocional e física, interferindo diretamente no estado psicológico e no emocional.

Sendo ainda um tema pouco conhecido no nosso ordenamento jurídico, faz-se necessário estudar o tema mais a fundo, pois a SMP pode engendrar práticas em que são cometidos delitos não observados, que por sua vez podem gerar sanções penais. Enxergado de forma precária, simplesmente como alienação parental, é imprescindível entrever o quanto complexo é avaliar as consequências. O diagnóstico ainda é muito precário, feito por meio de observação, o que transforma em uma linha muito tênue entre saber se o indivíduo possui ou não os sintomas desencadeados por ela, tornando ainda impreciso saber o que de fato a Síndrome de Munchausen por Procuração pode proporcionar e desenvolver.

Vale ressaltar que algumas pessoas podem usar do conhecimento sobre os aspectos e características da síndrome para o cometimento de delitos como a extorsão, fraudes contra serviços de saúde, lesão corporal, alienação parental e por fim até levar outras pessoas a óbito.

Utilizar-se da Síndrome de Munchausen é crime? Quais seriam as melhores sanções 
para quem é pego utilizando-se da síndrome para cometer delitos? Síndrome de Munchausen por Procuração é crime ou contravenção penal?

Ainda são muitas as perguntas que podem ser feitas a respeito desse tema, pois não se sabe ao certo o que de fato leva uma pessoa a ter tal transtorno ou a se utilizar do problema para obter benefícios. Se pensarmos que algumas pessoas podem, de forma espontânea, alegar que têm o transtorno para praticar delitos, pode existir ainda muitos delitos não observados pela justiça com casos envolvendo a Síndrome de Munchausen por Procuração, o que torna necessário e imprescindível que haja uma análise minuciosa para que se descubra quando o indivíduo possui ou não tal transtorno.

\section{REFERÊNCIAS}

ANGELIS NETO, Paschoal de. Alienação parental: uma abordagem social e jurídica entre os panoramas brasileiro e argentino. 2019. Disponível em: https://jus.com.br/artigos/73799/alienacao-parental. Acesso em: 22 out. 2019.

ANDRADE, Thamine Lessa Espírito Santo; PEREIRA-SILVA, Jorge L. Hemoptise fictícia na síndrome de Munchhausen: uma entidade a ser considerada no diagnóstico diferencial. 2005. Volume 31. Número 3. Disponível em: http://www.jornaldepneumologia.com.br/detalhe_artigo.asp?id=1137. Acesso em: 07 dez. 2019.

BITENCOURT, Cesar Roberto. Tratado de Direito Penal (Parte Geral). Vol. 1, 24. ed. São Paulo: Saraiva, 2018.

BRAGA, Mariana da Silva. 2007. Monografia. Especialização em psicologia clínica. Universidade Federal do Rio Grande do Sul. 21 f. Disponível em: https://www.lume.ufrgs.br/bitstream/handle/10183/12293/000606736.pdf?sequence=1. Acesso em: 20 nov. 2019.

BRANCO, Paulo Gustavo Gonet. Curso de Direito Constitucional. 8. ed. São paulo: Saraiva, 2013.

BRASIL. Alienação parental. Lei n. 12.318. 2010. Disponível em: http://www.planalto.gov.br/ccivil_03/_ato2007-2010/2010/lei/112318.htm. Acesso em: 22 out. 2019.

BRASIL. Código Civil. 2002. Disponível em: http://www.planalto.gov.br/ccivil_03/leis/2002/110406.htm. Acesso em: 28 nov. 2019.

BRASIL. Constituição da República Federativa do Brasil de 1988. Disponível em: http://www.planalto.gov.br/ccivil_03/constituicao/constituicaocompilado.htm. Acesso em 17 dez. 2019. 
BRASIL. Estatuto da Criança e do Adolescente. Lei n. 8.069. 1990. Disponível em: http://www.planalto.gov.br/ccivil_03/leis/18069.htm. Acesso em: 2 set. 2019.

CAISCAIS, Mafalda M. P. Síndroma de Munchausen por procuração, um desafio clínico. 2012. Artigo de revisão. Faculdade de Medicina da Universidade de Coimbra. $63 \mathrm{f}$. Disponível em: https://estudogeral.sib.uc.pt/bitstream/10316/81756/1/tese.pdf. Acesso em: 15 nov. 2019.

CAPEZ, Fernando. Curso de Direito Penal. 22. ed. São Paulo: Saraiva, 2018.

DIAS, Maria Berenice. Síndrome da Alienação Parental, o que é isso? Ministério Público do Estado do Pará - Procuradoria Geral de Justiça. Revista do Cao Cível, Belém, ano 11, n.5, jan-/dez. 2009. Disponível em: http://www.alienacaoparental.com.br/. Acesso em: 19 nov. 2019.

DSM-IV. Manual diagnóstico e estatístico de transtornos mentais. American Psychiatry Association. 4. ed. Madrid: Editorial Médica Panamericana, 1995.

HOUAISS, A. Dicionário da língua Portuguesa. São Paulo: Objetiva, 2009.

JESUS, Damásio de. Direito Penal (Parte Geral). 31. ed. São Paulo: Saraiva, 2010.

KAPLAN, H. I. ; SADOCK, B. J. Tratado de Psiquiatria. 6. ed. Porto Alegre: Artmed, 1999.

MURAHOVSCHI, et al. Síndrome de Munchausen por procuração: o caso da menina que sangrava pelo ouvido. Jornal de pediatria. Vol. 72, nº 1, 1996. Disponível em: http://www.jped.com.br/conteudo/96-72-01-35/port.pdf. Acesso em: 15 dez. 2019.

NUCCI, Guilherme de Souza. Manual de Direito Penal. (Parte Geral - Parte Especial) 8. ed. rev. atual e amp. São Paulo: Editora Revista dos Tribunais, 2012.

ORLANDO, Giovanna. R7.com. Disponível em: https://noticias.r7.com/internacional/maee-presa-acusada-de-matar-a-filha-com-doenca-terminal-nos-eua-24102019. Acesso em: 2 dez. 2019.

PUTINI, Julia. Mãe inventa doenças para a filha e enfrenta um destino trágico. R7.com. 2020. Disponível em: https://noticias.r7.com/hora-7/fotos/mae-inventa-doencas-para-a-filhae-enfrenta-um-destino-tragico-19022020\#!/foto/2. Acesso em: 13 dez. 2019.

REVISTA DE PROCESSO. São Paulo: Revista dos Tribunais, v. 25, n. 98, abr./jun. 20. 